\title{
Meios de cultura utilizados na micropropagação de híbridos de orquídeas
}

\section{Culture media used in the micropropagation of orchids hybrids}

\author{
Luzia Yuriko Miyata $^{1}$; Fabíola Villa ${ }^{2}$; Moacir Pasqual ${ }^{3}$
}

\begin{abstract}
Resumo
No cultivo de orquídeas, a cultura de tecidos tem se mostrado ferramenta importante e eficiente na obtenção de mudas de qualidade em larga escala e em curto espaço de tempo. Objetivou-se avaliar meios de cultura no crescimento e desenvolvimento de híbridos de orquídeas em cultivo in vitro. As plântulas com 1-1,5 cm de comprimento, oriundas da germinação in vitro de sementes, foram inoculadas em frascos de $250 \mathrm{~mL}$, contendo $50 \mathrm{~mL}$ de meio de cultura, com sais dos meios de seu respectivo tratamento. Os tratamentos consistiram na aplicação de meios de cultivo (MS; DSD1; Knudson; B5 e WPM), combinados com cinco híbridos de orquídeas (CW1, CW2, CW3, CI e BLC). Os meios foram acrescidos de $2 \mathrm{~g} \mathrm{~L}^{-1}$ de carvão ativado e solidificados com $5 \mathrm{~g} \mathrm{~L}^{-1}$ de ágar, sendo seus pH's ajustados para $5,8 \pm 0,1$, antes da autoclavagem a $121^{\circ} \mathrm{C}$ e a 1,1 atm por 20 minutos. Após esterilização dos meios, as plântulas foram inoculadas em câmara de fluxo laminar e posteriormente mantidas em sala de crescimento com temperatura de $25^{\circ} \mathrm{C} \pm 1$, fotoperíodo de 16 horas e irradiância de $32 \mu \mathrm{mol} \cdot \mathrm{m}^{-2} \cdot \mathrm{s}^{-1}$. $\mathrm{O}$ delineamento experimental foi inteiramente casualizado, em esquema fatorial 5x5, contendo 6 plântulas por repetição. Após 120 dias, avaliaram-se número raízes, número de brotos, comprimento das folhas e das raízes e biomassa fresca de raízes. No cultivo in vitro de orquídeas, os meios que se destacam são o MS e DSD1, e os híbridos CI, CW1 e BLC.

Palavras-chave: Floricultura, cultivo in vitro, Cattleya, Brassolaeliocattleya
\end{abstract}

\begin{abstract}
In orchid cultivation, tissue culture has been an important and effective tool for obtaining good quality seedlings on a large scale and within a short period of time. This study aims to evaluate culture media on the in vitro growth and development of orchid hybrids. Seedlings 1-1.5 cm long, deriving from in vitro germination of seeds, were inoculated in $250 \mathrm{~mL}$ flasks containing $50 \mathrm{~mL}$ of culture medium, with salts from the media where each of them were treated. Treatments consisted of applying culture media (MS; DSD1; Knudson; B5; and WPM), combined with 5 orchid hybrids (CW1, CW2, CW3, CI e BLC). The media were added $2 \mathrm{~g} \mathrm{~L}^{-1}$ of activated charcoal and solidified with $5 \mathrm{~g} \mathrm{~L}^{-1}$ of agar, and their $\mathrm{pH}$ was adjusted to $5.8 \pm 0.1$, before autoclaving at $121^{\circ} \mathrm{C}$ and at $1.1 \mathrm{~atm}$ for 20 minutes. After sterilization of media, seedlings were inoculated in a laminar flow chamber and then kept in a growth room at the temperature of $25 \pm 1^{\circ} \mathrm{C}$, with photoperiod of $16 \mathrm{~h}$ and irradiance of $32 \mu \mathrm{mol} \cdot \mathrm{m}^{-2} \cdot \mathrm{s}^{-1}$. The experimental design was completely randomized, in a factorial 5 x 5 scheme, containing 6 seedlings per repetition. After 120 days, we evaluated root number, shoot number, leaf and root length, and fresh root weight. In in vitro cultivation of orchids, the media standing out are MS and DSD1 and the hybrids CI, CW1, and BLC.
\end{abstract}

Key words: Floriculture, in vitro cultivation, Cattleya, Brassolaeliocattleya

\footnotetext{
${ }^{1}$ Discente do Curso de Doutorado em Ciências, Escola Superior de Agricultura "Luiz de Queiroz", ESALQ, Piracicaba, SP. E-mail: lymiyata@esalq.usp.br

${ }^{2}$ Prof $^{\mathrm{a}} \mathrm{Dr}^{\mathrm{a}}$, Centro de Ciências Agrárias, CCA, Universidade Estadual do Oeste do Paraná, UNIOESTE, Campus Marechal Cândido Rondon, PR. E-mail: fvilla2003@hotmail.com

${ }^{3}$ Prof. Dr., Dept ${ }^{\circ}$ de Agricultura, DAG, Universidade Federal de Lavras, UFLA, Lavras, MG. E-mail: mpasqual@ufla.br

* Autor para correspondência
} 


\section{Introdução}

A família Orchidaceae é considerada a mais numerosa de todo reino vegetal, sendo encontrada em todos os continentes, com exceção das regiões desérticas, Ártico e Antártida. Ocorre mais significativamente nos trópicos, sendo o Brasil a segunda maior concentração de espécies no planeta. Um elevado número de espécies e híbridos possibilita a ocorrência de grande variedade de cores e formas, o que as torna de grande importância econômica (CAMPOS, 2008).

A propagação de orquídeas pode ser tanto vegetativa, quanto por meio de sementes. Estas, embora produzidas em grande quantidade, não possuem endosperma funcional, sendo incapazes de germinar e tornarem-se adultas sem que haja a associação de fungos micorrízicos (DEARNALEY, 2007).

A hibridação natural entre gêneros e/ou espécies é pouco frequentemente e os métodos convencionais de propagação vegetativa, como divisão da planta não atende as necessidades comerciais. Neste contexto, a produção de orquídeas a partir de técnicas de cultura de tecidos é a alternativa viável para a obtenção de grande número de plantas com alta qualidade genética e fitossanitária, em curto espaço de tempo, suprindo assim a necessidade dos produtores de orquídeas na produção de mudas com qualidade comprovada.

Os fatores que mais freqüentemente determinam o sucesso da micropropagação de espécies vegetais são a fonte do explante e o meio nutritivo onde são cultivados (PASQUAL; HOFFMANN; RAMOS, 2001).

Diversos meios de cultivo podem ser empregados para propagação in vitro de orquídeas. O meio de cultura padrão utilizado, porém não é o mais adequado, é o MS (MURASHIGE; SKOOG, 1962), composto de macronutrientes, micronutrientes, vitaminas, Fe-EDTA, sacarose e ágar, acrescido de carvão ativado. Embora seja o meio mais utilizado pela maioria dos produtores, apresenta um custo significativamente alto que incide no aumento do custo de produção (SU; SCHNITZER; FARIA, 2012).

Não existe, ainda, um meio de cultura específico adequado para um gênero, espécie, híbrido ou clone. Em geral, é difícil explicar porque em certas combinações de componentes do meio e condições de cultivo os resultados têm sido bem sucedidos, enquanto em outras não se tem logrado êxito (FRÁGUAS et al., 2003; VENTURA, 2007).

O maior entrave no processo de micropropagação de orquídeas está relacionado ao tempo necessário para a produção de mudas e a utilização de meio de cultura adequado para cada espécie. Assim, objetivou-se testar diferentes meios de cultura na micropropagação in vitro de híbridos de orquídea.

\section{Material e Métodos}

O trabalho foi realizado na Universidade Federal de Lavras (UFLA), MG. As sementes resultantes cruzamento foram germinadas em meio Knudson C (KNUDSON, 1946), acrescido de 40 g.L $\mathrm{L}^{-1}$ de polpa de banana e $100 \mathrm{~mL} . \mathrm{L}^{-1}$ de água de coco. Após a germinação (90 dias), foram repicadas para meio idêntico ao da germinação.

Os tratamentos consistiram de cinco meios de cultivo (MS; DSD1; Knudson; B5; WPM), combinados com os híbridos (Tabela 1).

Os meios de cultura foram acrescidos de 2 g.L $\mathrm{L}^{-1}$ de carvão ativado e solidificados com 5 g.L${ }^{1}$ de ágar, sendo o $\mathrm{pH}$ ajustado para $5,8 \pm 0,1$, antes da esterilização a $121^{\circ} \mathrm{C}$, sob $1,1 \mathrm{~atm}$, durante 20 minutos. Após esterilização, as plântulas foram inoculadas, sob condições assépticas em câmara de fluxo laminar e posteriormente transferidas para sala de crescimento, sob $25^{\circ} \mathrm{C} \pm 1$, fotoperíodo de 16 horas e irradiância de $32 \mu \mathrm{mol} \cdot \mathrm{m}^{-2} \cdot \mathrm{s}^{-1}$ (luz fria). As plântulas com $1-1,5 \mathrm{~cm}$ foram cultivadas em frascos de vidro $(250 \mathrm{~mL})$ contendo $50 \mathrm{~mL}$ de meio de cultivo. 
Tabela 1. Diferentes híbridos de orquídeas micropropagados em meios de cultivo. UFLA, 2013.

\begin{tabular}{cl}
\hline Sigla & Híbridos \\
\hline CW1 & Cattleya walkeriana cv. (Alba Equilab x tipo) \\
CW2 & Cattleya walkeriana cv. (Silveira x tipo) \\
CW3 & Cattleya walkeriana cv. (Suave Poços x Coerulea) \\
CI & Cattleya intermedia cv. orlata \\
BLC & Brassolaeliocattleya George King Serenity x Brassolaeliocattleya Vallezac Magic Fire \\
\hline
\end{tabular}

Fonte: Elaboração dos autores.

O delineamento experimental foi inteiramente casualizado, em esquema bi-fatorial $5 \times 5$, contendo quatro repetições, com 6 plântulas por repetição. Após 120 dias de cultivo, foram avaliados os seguintes parâmetros biométricos: número de raízes, número de brotos, comprimento foliar $(\mathrm{cm})$, comprimento radicular $(\mathrm{cm})$ e biomassa fresca radicular $(\mathrm{g})$. A análise de variância foi realizada utilizando software estatístico SISVAR (FERREIRA, 2011), pelo teste de médias ScottKnott.

\section{Resultados e Discussão}

De acordo com a análise de variância, pode-se observar interação significativa para número de raízes, número de brotos, comprimento radicular e biomassa fresca radicular dos híbridos de orquídea.

Analisando o número de brotos (Tabela 2), verificou-se que o meio de cultivo MS se sobressaiu em relação aos demais empregados, quando utilizado na micropropagação de BLC. Maior número de brotos foi observado no cultivo in vitro de BLC, em meio de cultura MS, em relação aos demais meios.

Tabela 2. Número de brotos de híbridos de orquídea cultivados em diferentes meios de cultivo. UFLA, Lavras, MG. 2013.

\begin{tabular}{llllll}
\hline \multicolumn{7}{c}{ Híbridos } \\
\hline MC & CW1 & CW2 & CW3 & CI & BLC \\
\hline MS & $2,306^{\text {n.s. }}$ & $3,546 \mathrm{aB} *$ & $3,209 \mathrm{aB}$ & $3,502 \mathrm{aB}$ & $4,530 \mathrm{aA}$ \\
DSD1 & $2,221^{\text {n.s. }}$ & $2,394 \mathrm{bB}$ & $3,399 \mathrm{aA}$ & $3,572 \mathrm{aA}$ & $3,601 \mathrm{bA}$ \\
Knudson & $2,783^{\text {n.s. }}$ & $3,315 \mathrm{aA}$ & $2,212 \mathrm{bA}$ & $2,675 \mathrm{bA}$ & $2,908 \mathrm{cA}$ \\
B5 & $2,702^{\text {n.s. }}$ & $3,326 \mathrm{aA}$ & $2,513 \mathrm{bB}$ & $2,474 \mathrm{bB}$ & $3,181 \mathrm{bA}$ \\
WPM & $2,516^{\text {n.s. }}$ & $2,335 \mathrm{~b}$ & $2,552 \mathrm{~b}$ & $2,865 \mathrm{~b}$ & $2,450 \mathrm{c}$ \\
\hline CV $(\%)$ & \multicolumn{5}{c}{18,02} \\
\hline
\end{tabular}

*Letras minúsculas diferem entre si na linha e maiúsculas na coluna, a 5\% de probabilidade. MC = meios de cultura.

Fonte: Elaboração dos autores.

Este resultado pode ser explicado pela maior concentração de nitrogênio (840,90 mg L $\left.\mathrm{L}^{-1}\right)$ presente no meio MS. Este nutriente, juntamente com a sacarose, é o principal componente em quantidade no meio de cultura, contribuindo de forma efetiva, tanto no metabolismo celular, como na regulação do seu potencial osmótico (NAGAO; PASQUAL; RAMOS, 1994). Resultados deste trabalho corroboram Pasqual et al. (2009) que, a partir da elevação na concentração de $\mathrm{NH}_{4} \mathrm{NO}_{3}$ no meio de cultura MS, obtiveram aumento no número de brotações de plantas de orquídeas.

O meio WPM não se mostrou eficiente no número de brotos e propagação in vitro dos híbridos de orquídea (Tabela 2). A quantidade de nutrientes 
do meio Knudson parece influenciar o número de brotos emitidos pelos explantes dos híbridos de orquídea estudados, evidenciando assim uma deficiência em nutrientes neste meio de cultivo. Este meio de cultura possui baixos teores em sais nutritivos, quando comparado com outros meios, como o MS (GEORGE; HALL; DE KLERK, 2008).

Na Tabela 3 verifica-se a formação do sistema radicular dos híbridos de orquídea cultivados em diferentes meios de cultivo. Melhores resultados foram observados na micropropagação do híbrido CI, nos meios de cultivo estudados.
No meio DSD1 observou-se maior número de raízes para o híbrido CI. Este meio de cultura é rico em vitaminas, favorecendo a formação de raízes das plântulas (polpa de banana promove a formação de raízes). Com o aumento no número de raízes, aumenta-se a área de contato raiz/substrato, refletindo em maior absorção dos nutrientes. Este resultado é importante para a fase de transplantio de mudas, podendo favorecer assim, maior sobrevivência (Tabela 3).

Tabela 3. Número de raízes de híbridos de orquídea cultivados em diferentes meios de cultivo. UFLA, Lavras, MG. 2013.

\begin{tabular}{lccccc}
\hline \multicolumn{5}{c}{ Híbridos } \\
\hline MC & CW1 & CW2 & CW3 & CI & BLC \\
\hline MS & $2,937 \mathrm{bC}^{*}$ & $3,445^{\text {n.s. }}$ & $4,652 \mathrm{aA}$ & $5,060 \mathrm{bA}$ & $3,833 \mathrm{bB}$ \\
DSD1 & $3,313 \mathrm{bC}$ & $3,411^{\text {n.s. }}$ & $4,089 \mathrm{bB}$ & $6,121 \mathrm{aA}$ & $4,582 \mathrm{aB}$ \\
Knudson & $3,152 \mathrm{bB}$ & $3,384^{\text {n.s. }}$ & $3,645 \mathrm{bB}$ & $4,858 \mathrm{bA}$ & $3,764 \mathrm{bB}$ \\
B5 & $2,989 \mathrm{bB}$ & $3,350^{\text {n.s. }}$ & $3,653 \mathrm{bB}$ & $4,721 \mathrm{bA}$ & $4,086 \mathrm{bA}$ \\
WPM & $4,186 \mathrm{aB}$ & $3,793^{\text {n.s. }}$ & $4,912 \mathrm{aA}$ & $5,615 \mathrm{aA}$ & $5,123 \mathrm{aA}$ \\
\hline CV $(\%)$ & & \multicolumn{5}{c}{12,81} \\
\hline
\end{tabular}

*Letras minúsculas diferem entre si na linha e maiúsculas na coluna, a 5\% de probabilidade. $\mathrm{MC}=$ meios de cultura.

Fonte: Elaboração dos autores.

Para o comprimento do sistema radicular, verifica-se na Tabela 4 interação significativa apenas para o híbrido CW1, micropropagado nos diferentes meios de cultivo, sendo maior comprimento das raízes observado no meio de cultivo MS. Pode-se inferir desta forma, que as vitaminas, aminoácidos e sacarose do meio MS contribuíram no comprimento das raízes do híbrido, influenciando positivamente o enraizamento in vitro (SCHNEIDERS et al., 2012).

O meio MS é conhecido por ser um meio altamente concentrado tendo, em sua composição, altas concentrações de nitrogênio (840,90 $\left.\mathrm{mg} \mathrm{L}^{-1}\right)$, cálcio $\left(119,98 \mathrm{mg} \mathrm{L}^{-1}\right)$, manganês $\left(1,08 \mathrm{mg} \mathrm{L}^{-1}\right) \mathrm{e}$ zinco $\left(1,96 \mathrm{mg} \mathrm{L}^{-1}\right)$. Por essas atribuições este meio teve bom desempenho no comprimento do sistema radicular de plantas do híbrido CW1 cultivadas in vitro, pois esses nutrientes são requeridos no processo de crescimento de raízes.

Na Tabela 5 observa-se significância para meios de cultura e os híbridos, separadamente, em relação ao comprimento foliar. Os meios de cultivo que se destacaram foram o DSD1 (SILVA; DOAZAN, 1995) e WPM (LLOYD; McCOWN, 1980). Para os híbridos, melhores resultados foram verificados para os híbridos CW1, CW2 e BLC. 
Tabela 4. Comprimento radicular de híbridos de orquídea cultivados em diferentes meios de cultivo. UFLA, Lavras, MG. 2013.

\begin{tabular}{|c|c|c|c|c|c|}
\hline & \multicolumn{5}{|c|}{ Híbridos } \\
\hline $\mathrm{MC}$ & CW1 & CW2 & CW3 & CI & BLC \\
\hline MS & $2,343 \mathrm{a}^{*}$ & $1,306^{\text {n.s. }}$ & $1,350^{\text {n.s. }}$ & $1,178^{\text {n.s. }}$ & $1,106^{\text {n.s. }}$ \\
\hline DSD1 & $1,376 \mathrm{~b}$ & $1,042^{\text {n.s. }}$ & $1,138^{\text {n.s. }}$ & $1,290^{\text {n.s. }}$ & $1,145^{\text {n.s. }}$ \\
\hline Knudson & $1,260 \mathrm{~b}$ & $1,017^{\text {n.s. }}$ & $1,216^{\text {n.s. }}$ & $1,167^{\text {n.s. }}$ & $1,184^{\text {n.s. }}$ \\
\hline B5 & $1,531 \mathrm{~b}$ & $1,158^{\text {n.s. }}$ & 1,297 n.s. & $1,276^{\text {n.s. }}$ & $1,131^{\text {n.s. }}$ \\
\hline WPM & $1,560 \mathrm{~b}$ & $1,338^{\text {n.s. }}$ & $1,367^{\text {n.s. }}$ & $1,344^{\text {n.s. }}$ & $1,204^{\text {n.s. }}$ \\
\hline CV (\%) & & & 22,10 & & \\
\hline
\end{tabular}

*Letras minúsculas diferem entre si na coluna, a 5\% de probabilidade. $\mathrm{MC}=$ meios de cultura.

Fonte: Elaboração dos autores.

Embora o meio MS favoreça o crescimento e desenvolvimento de várias espécies vegetais, a utilização de composições mais diluídas, como o meio DSD1 e 1/2MS (GALDIANO JUNIOR et al., 2012), para algumas espécies de orquídeas e alguns híbridos de Cattleya, tem fornecido melhores resultados (AKTAR; NASIRUDDIN; HOSSAIN, 2008).

As proporções do meio DSD1 e WPM influenciaram positivamente o comprimento foliar dos híbridos, sendo esta uma influência direta do aumento no teor de nutrientes (Tabela 5). Carlucci, Haag e Bellote (1989) afirmam que os gêneros Cattleya e Laelia são exigentes em zinco (Zn). O Zn desempenha importante função no metabolismo de crescimento das plântulas e, segundo alguns autores, existe necessidade do aumento da disponibilidade desse nutriente em meio de cultura para melhor crescimento de híbridos (FIGUEIREDO et al., 2007).

Tabela 5. Comprimento foliar de híbridos de orquídea cultivados em diferentes meios de cultivo. UFLA, Lavras, MG. 2013.

\begin{tabular}{lc}
\hline Meios de cultura & CF \\
\hline MS & $1,821 \mathrm{~b}^{*}$ \\
DSD1 & $2,012 \mathrm{a}$ \\
Knudson & $1,772 \mathrm{~b}$ \\
B5 & $1,857 \mathrm{~b}$ \\
WPM & $1,906 \mathrm{a}$ \\
\hline CV $(\%)$ & 13,26 \\
\hline Híbridos & $\mathrm{CF}$ \\
\hline CW1 & $2,038 \mathrm{a}^{*}$ \\
CW2 & $2,056 \mathrm{a}$ \\
CW3 & $1,688 \mathrm{~b}$ \\
CI & $1,556 \mathrm{~b}$ \\
BLC & $2,030 \mathrm{a}$ \\
\hline CV $(\%)$ & 13,26 \\
\hline
\end{tabular}

*Letras minúsculas diferem entre si na coluna, a 5\% de probabilidade. $\mathrm{CF}=$ comprimento foliar.

Fonte: Elaboração dos autores. 
$\mathrm{Na}$ Tabela 6 verifica-se a interação significativa para a biomassa fresca das raízes dos híbridos cultivados em diferentes meios de cultivo. Maior biomassa foi obtida no híbrido CI, nos diversos meios.

Todos os meios estudados possuem quantidades balanceadas de macro e micronutrientes na sua formulação, indicados para cada tipo de genótipo vegetal estudado. A importância deste elemento está relacionada com a síntese de proteínas, aminoácidos e ácidos nucléicos; tem papel importante na produção de triptofano, precursor natural do AIA e de substâncias de reserva. O zinco e o manganês influenciam o nível de auxinas endógenas; o cálcio é necessário para o crescimento e desenvolvimento das raízes visto que a interrupção no seu suprimento resulta imediatamente na não formação dos primórdios de raízes e, se já formadas, na redução do crescimento e conseqüente morte (BLAZICH, 1988).

Tabela 6. Biomassa fresca das raízes de híbridos de orquídea cultivados em diferentes meios de cultivo. UFLA, Lavras, MG. 2013.

\begin{tabular}{lccccc}
\hline & \multicolumn{5}{c}{ Híbridos } \\
\hline MC & CW1 & CW2 & CW3 & CI & BLC \\
\hline MS & $1,307 \mathrm{aB}$ & 1,065 n.s. & $1,660 \mathrm{aA}$ & $1,695 \mathrm{aA}$ & $1,223 \mathrm{bB}$ \\
DSD1 & $1,017 \mathrm{bC}$ & 0,901 n.s. & $1,202 \mathrm{bB}$ & $1,833 \mathrm{aA}$ & $1,101 \mathrm{bB}$ \\
Knudson & $0,971 \mathrm{bB}$ & 0,878 n.s. & $1,045 \mathrm{bB}$ & $1,265 \mathrm{bA}$ & $1,059 \mathrm{bB}$ \\
B5 & $1,056 \mathrm{bA}$ & 0,938 n.s. & $1,279 \mathrm{bB}$ & $1,783 \mathrm{aA}$ & $1,132 \mathrm{bB}$ \\
WPM & $1,357 \mathrm{aC}$ & 1,101 n.s. & $1,518 \mathrm{aB}$ & $1,781 \mathrm{aA}$ & $1,390 \mathrm{aC}$ \\
\hline CV $(\%)$ & \multicolumn{5}{c}{12,78} \\
\hline
\end{tabular}

*Letras minúsculas diferem entre si na linha e maiúsculas na coluna, a 5\% de probabilidade. $\mathrm{MC}=$ meios de cultura.

Fonte: Elaboração dos autores.

De acordo com os resultados acima observados, tornou-se claro a necessidade de se adequar para cada híbrido um meio de cultura, haja vista que o comportamento é influenciado pelo meio empregado.

Existe grande variedade de meios de cultivo para micropropagação. Entretanto, a maioria das descrições de preparos de meios alternativos não demonstra de maneira comparativa se o novo meio é ou não melhor que o outro do qual foi originado. Esse deve ser selecionado em função da espécie e tipo de cultivo que está sendo efetivado (PASQUAL; HOFFMANN; RAMOS, 1997).

O crescimento de plantas, órgãos, tecidos e células in vitro depende do desenvolvimento de meios de cultura otimizados para a perfeita interação de componentes essenciais como fontes de carbono e nutrientes. Os fatores que limitam esse crescimento são similares àqueles que limitam in vivo. Várias mudanças de padrão foram propostas na tentativa de otimizar este crescimento. Essas alterações visam principalmente a redução ou incremento de alguns componentes, como por exemplo, os macro e micronutrientes, vitaminas e aminoácidos; que podem promover melhor crescimento em tecidos vegetais (SORACE et al., 2008), e diminuir o tempo de formação de mudas de híbridos de orquídeas.

\section{Conclusão}

No cultivo in vitro de orquídeas, os meios que se destacam são o MS e DSD1, e os híbridos CI, CW1 e BLC. 


\section{Referências}

AKTAR, S.; NASIRUDDIN, K. M.; HOSSAIN, $\mathrm{K}$. Effects of different media and organic additives interaction on in vitro regeneration of Dendrobium orchid. Journal of Agriculture \& Rural Development, Bangladesh, v. 61, n. 1-2, p. 69-74, 2008.

BLAZICH, F. A. Mineral nutrition and adventitious rooting. In: DAVIES, T. D.; HAISSIG, B. E.; SANKHLA, N. Adventitious root formation in cuttings. Portland: Dioscorides Press, 1988. p. 61-69 (Advances in Plant Sciences Series, 2).

CAMPOS, F. A. D. B. Considerações sobre a Família Orquidaceae: taxonomia, antropismo, valor econômico e tecnologia. O mundo da saúde, São Paulo, v. 32, n. 3, p. 383-392, 2008.

CARLUCCI, M. V.; HAAG, H. P.; BELlOTE, A. F. J. Composição química e extração de nutrientes por cinco espécies de Orchidaceae. In: HAAG, H. P.; MINAMI, K.; LIMA, A. M. L. P. Nutrição mineral de algumas espécies ornamentais. Campinas: Fundação Cargill, 1989. p. 254267.

DEARNALEY, J. D. W. Further advances in orchid mycorrhizal research. Mycorrhiza, Alemanha, v. 17, n. 6, p. $475-486,2007$.

FERREIRA, D. F. Sisvar: a computer statistical analysis system. Ciência \& Agrotecnologia, Lavras, v. 35, n. 6, p. 1039-1042, 2011.

FIGUEIREDO, M. A.; SANTOS, F. M.; SILVA, J. O. C.; COSTA, F. H. S.; PASQUAL, M. Variações no meio de cultura sobre o crescimento in vitro em híbridos de orquídea. Revista Brasileira de Biociências, Porto Alegre, v. 5, p. 294-296, 2007. Suplemento 2.

FRÁGUAS, C. B.; VILLA, F.; SOUZA,A. V.; PASQUAL, M.; DUTRA, L. F. Crescimento in vitro de plântulas de orquídeas oriundas da hibridação entre Cattleya labiata e Laelia itambana. Revista Ceres, Viçosa, v. 50, n. 292, p. 719-726, 2003.

GALDIANO JUNIOR, R. F.; MANTOVANI, C.; PIVETTA, K. F. L.; LEMOS, E. G. M. Crescimento in vitro e aclimatização de Cattleya loddigesii Lindley (Orchidaceae) com carvão ativado sob dois espectros luminosos. Ciência Rural, Santa Maria, v. 42, n. 5, p. 801-807, 2012.

GEORGE, E. F.; HALL, M. A.; DE KLERK, G. J. Plant propagation by tissue culture. Dordrecht: The Background, 2008. $501 \mathrm{p}$.

KNUDSON, L. A new nutrient solution for the germination of orchid seed. American Orchid Society Bulletin, West Palm Beach, v. 14, n. 2, p.214- 217, 1946.
LLOYD, G.; McCOWN, B. Commercially-feasible micropropagation of mountain laurel, Kalmia latifolia, by use of shoot-tip culture. International Plant Propagation Society Proceedings, Seattle, v. 30, n. 2, p. 421-427, 1980.

MURASHIGE, T.; SKOOG, F. A revised medium for rapid growth and bio assays with tobacco tissue cultures. Physiologia Plantarum, Copenhagen, v. 15, n. 3, p. 473497, 1962.

NAGAO, E. O.; PASQUAL, M.; RAMOS, J. D. Efeitos da sacarose e do nitrogênio inorgânico sobre a multiplicação in vitro de brotações de porta-enxerto de citros. Bragantia, Campinas, v. 53, n. 1, p. 25-31, 1994.

PASQUAL, M.; FIGUEIREDO, M. A.; REZENDE, J. C.; ARAÚJO, A. G.; SANTOS, F. C.; FERREIRA, E. A.; JUNQUEIRA, K. P. Fontes de nitrogênio, polpa de banana e ágar no desenvolvimento in vitro de plântulas de orquídea. Horticultura Brasileira, Brasília, v. 27, n. 2, p. 211-216, 2009.

PASQUAL, M.; HOFFMANN, A.; RAMOS, J. D. Cultura de tecidos vegetais: tecnologia e aplicação. Lavras: UFLA/FAEPE, 1997. 159 p.

PASQUAL, M.; HOFFMANN, A.; RAMOS, J. D. Cultura de tecidos: tecnologia e aplicação. Introdução: situação e perspectivas. Lavras: UFLA/FAEPE, 2001. 72 p.

SCHNEIDERS, D.; PESCADOR, R.; BOOZ, M. R.; SUZUKI, R. M. Germinação, crescimento e desenvolvimento in vitro de orquídeas (Cattleya spp., Orchidaceae). Revista Ceres, Viçosa, v. 59, n. 2, p. 185191, 2012.

SILVA, A. L.; DOAZAN, J. P. Une méthode d'irradiation aux rayons gamma appliquée à des porte-greffes de Vigne in vitro. Journal International Science of Vigne et Vin, França, v. 29, n. 1, p. 1-9, 1995.

SORACE, M.; FARIA, R. T.; DAMASCENO JUNIOR, C. V.; GOMES, G. P.; BARBOSA, C. M.; VIEIRA, F. G. N.; SILVA, G. L.; TAKAHASHI, L. S. A.; SCHNITZER, J. A. Crescimento in vitro de Oncidium baueri (Orchidaceae) em diferentes concentrações de macronutrientes e sacarose. Revista de Ciências Agrárias, Recife, v. 29, n. 4, p. 775-782, 2008.

SU, M. J.; SCHNITZER, J. A.; FARIA, R. T. Polpa de banana e fertilizantes comerciais no cultivo in vitro de orquídea. Cientifica, Jaboticabal, v. 40, n. 1, p. 28-34, 2012.

VENTURA, G. M. Cultivo in vitro de orquídeas do grupo Cattleya, em diferentes meios de cultura e irradiancias. 2007. Tese (Doutorado em Fitotecnia) - Universidade Federal de Viçosa, Viçosa, MG. 
